\title{
Evidence for perceptual neglect of environmental features in hippocampal-lesioned pigeons during homing
}

\author{
Anna Gagliardo, ${ }^{1}$ Enrica Pollonara, ${ }^{1}$ Vincent J. Coppola, ${ }^{2}$ Carlos D. Santos, ${ }^{3,4}$ Martin Wikelski ${ }^{3,5}$ and \\ Verner P. Bingman ${ }^{2}$ \\ ${ }^{1}$ Department of Biology, University of Pisa, Via Volta 6, 56126 Pisa, Italy \\ ${ }^{2}$ Department of Psychology and J. P. Scott Center for Neuroscience, Mind and Behavior, Bowling Green State University, \\ Bowling Green, OH, USA \\ ${ }^{3}$ Department of Migration and Immuno-Ecology, Max Planck Institute for Ornithology, Radolfzell, Germany \\ ${ }^{4}$ Departamento de Biologia, Centro de Ciências Biológicas e da Saúde, Universidade Federal do Maranhão, São Luís, MA, \\ Brazil \\ ${ }^{5}$ Department of Biology, University of Konstanz, Konstanz, Germany
}

Keywords: Columba livia, hippocampus, navigation, spatial cognition

\begin{abstract}
The importance of the vertebrate hippocampus in spatial cognition is often related to its broad role in memory. However, in birds, the hippocampus appears to be more specifically involved in spatial processes. The maturing of GPS-tracking technology has enabled a revolution in navigation research, including the expanded possibility of studying brain mechanisms that guide navigation in the field. By GPS-tracking homing pigeons released from distant, unfamiliar sites prior to and after hippocampal lesion, we observed, as has been reported previously, impaired navigational performance post-lesion over the familiar/memorized space near the home loft, where topographic features constitute an important source of navigational information. The GPS-tracking revealed that many of the lost pigeons, when lesioned, approached the home area, but nevertheless failed to locate their loft. Unexpectedly, when they were hippocampal-lesioned, the pigeons showed a notable change in their behaviour when navigating over the unfamiliar space distant from home; they actually flew straighter homeward-directed paths than they did pre-lesion. The data are consistent with the hypothesis that, following hippocampal lesion, homing pigeons respond less to unfamiliar visual, topographic features encountered during homing, and, as such, offer the first evidence for an unforeseen, perceptual neglect of environmental features following hippocampal damage.
\end{abstract}

\section{Introduction}

The avian hippocampal formation (HF) participates in a range of spatial cognitive behaviours (Sherry \& Vaccarino, 1989; Hampton \& Shettleworth, 1996; Colombo \& Broadbent, 2000; Bingman et al., 2003; Shiflett et al., 2003; Watanabe \& Bischof, 2004; Mayer et al., 2009). Many of the cited studies took place in the restrictive space of semi natural settings, where the tasks principally tested for spatial memory/goal recognition. Research in homing pigeons, by contrast, has emphasized the role of the avian HF in navigational processes that guide homing over distances of tens of kilometres (Bingman et al., 2005). The principal finding that emerges from the field work in homing pigeons is that the HF is necessary when pigeons navigate by familiar landmarks or land scape features near the home loft (Bingman et al., 1988; Bingman \& Mench, 1990) or along a familiar route (Gagliardo et al., 2009). In contrast, the HF was concluded to play no role in navigation over unfamiliar space, a conclusion based entirely on experiments

Correspondence: Anna Gagliardo, as above.

E-mail: anna.gagliardo@unipi.it that relied on the recording of vanishing bearings (Bingman et al., 1984, 1988). As such, the existing data on the relationship between the HF and long distance navigation from unfamiliar sites are rela tively impoverished with respect to information content, potentially masking subtle effects of HF lesions beyond the area of familiarity, and revealing nothing about the routes that pigeons take from an unfamiliar release site to the home loft. Clearly, a more complete profile of how HF lesions impact on pigeon navigation during homing would allow better characterization of how the HF partici pates more broadly in spatial cognition. For example, in one GPS tracking study, carried out in pigeons homing over familiar space (Gagliardo et al., 2009), the behaviour of HF lesioned pigeons in proximity to a significant landscape boundary (a coastline) sug gested that they perceptually neglected the boundary that separated land from sea. In fact, whereas the coastline was a salient topo graphical feature inducing homeward directed re orientation in clock shifted intact pigeons, the clock shifted HF lesioned pigeons regularly ignored the land sea boundary, often flying over the sea for several kilometres.

The recent advances in tracking technology have revolutionized animal navigation research (Guilford et al., 2011), including studies 
on homing pigeon navigation, in which GPS data loggers with (e.g. Gagliardo et al., 2011b) and without (e.g. Biro et al., 2004) transmission capabilities have provided a far richer understanding of how pigeons navigate home. In the current study, we returned to the foundation question of our investigations into the role of the HF in homing pigeon spatial cognition: what effects do HF lesions have on the behaviour of pigeons when they are released from a distant, unfamiliar location (Bingman et al., 1984)? However, we address this question with state of the art GPS tracking technology, to: (i) fully characterize the flight behaviour of HF lesioned pigeons in the familiar area near the loft, in order to provide a more complete understanding of why their navigation here is impoverished; and, more importantly, (ii) revisit the question of whether HF lesions also impact on navigational performance closer to the release site and outside the area that would be familiar to pigeons.

\section{Materials and methods}

\section{General procedure}

Forty three experienced homing pigeons, 2 years of age and hatched at the Arnino field station (Arnino, Pisa, Italy), were used in the experiment, which took place in three consecutive years (2011 2013). The pigeons were bred as free flyers, and were kept accord ing to Italian law on animal welfare. The homing experience of the pigeons was limited to one single release from the east or south at a distance of approximately $4050 \mathrm{~km}$. Prior to the experiment, each pigeon was equipped with a PVC dummy weight, similar in dimension and weight ( $3032 \mathrm{~g}$ ) to the GPS data logger that they would be carrying (see below), in order to accustom them to flying with a load. The dummy was attached to the pigeon's back by means of a Velcro strip glued to the feathers, which had been trimmed.

To generate a baseline performance comparison for this within subject investigation, prior to lesion surgery (pre lesion condition) all 43 pigeons were equipped with a GPS data logger and experi mentally released from an unfamiliar release site (see below for details on the release sites). GPS recordings from 10 pigeons failed to yield complete tracks, and they were excluded from the rest of the experiment. The remaining 33 pigeons, which yielded complete tracks, all of whom returned home on the day of the release or the day after, were then subjected to bilateral ablation of the HF (see below for lesion surgery details). At least 20 days after lesion sur gery (during the interval, the pigeons were returned to their home loft but were not allowed free flights around the loft), each pigeon was then released again from a different unfamiliar site, which was located in a different direction with respect to home than the pre lesion release site. In the pre lesion condition, 18 pigeons were released from Bientina $\left(43^{\circ} 42^{\prime} 46^{\prime \prime} \mathrm{N} ; 10^{\circ} 36^{\prime} 49^{\prime \prime} \mathrm{E}\right.$; home direction, $255^{\circ}$; distance, $25.6 \mathrm{~km}$ ); in the post lesion condition, nine of them were released from Casciana Terme $\left(43^{\circ} 30^{\prime} 58^{\prime \prime} \mathrm{N}\right.$; $10^{\circ} 37^{\prime} 21^{\prime \prime} \mathrm{E}$; $\left.303^{\circ} ; 30.0 \mathrm{~km}\right)$ and the remaining nine from Fauglia $\left(43^{\circ} 34^{\prime} 04^{\prime \prime} \mathrm{N}\right.$; $10^{\circ} 30^{\prime} 21^{\prime \prime} \mathrm{E} ; 302^{\circ} ; 19.0 \mathrm{~km}$ ). Another eight pigeons were released from Fauglia in the pre lesion condition, and then released from Tassignano $\left(43^{\circ} 49^{\prime} 42^{\prime \prime} \mathrm{N} ; 10^{\circ} 34^{\prime} 18^{\prime \prime} \mathrm{E} ; 227^{\circ} ; 28.7 \mathrm{~km}\right)$ in the post lesion condition. The last seven pigeons were released from Tassig nano in the pre lesion condition and from Fauglia in the post lesion condition. The mixture of release sites was chosen to contrast the flight path of pigeons from unfamiliar locations before and after HF lesion in such a way as to diminish any effects of release site as such.

\section{Surgery}

For the bilateral HF lesions, pigeons were first anaesthetized with an intramuscular injection of $20 \%$ chloral hydrate $(2 \mathrm{~mL} / \mathrm{kg}$ body weight). The lesion target coordinates were stereotaxically identi fied according to the pigeon brain atlas (Karten \& Hodos, 1967), and bilateral aspiration lesions were targeted to the hippocampus and parahippocampus. The procedures used were identical to those described in previous publications (Bingman et al., 1984; Gag liardo et al., 2009). The project was approved by the Scientific Ethics Committee of the University of Pisa (CASA, permit number 8630), and was carried out in accordance with EU Direc tive 2010/63/EU on the protection of animals used for scientific purposes.

\section{GPS data logger}

For the pre lesion condition releases, we used I Got U GPS loggers (weight, $22 \mathrm{~g}$; sampling rate, $1 \mathrm{~Hz}$ ). For the post lesion condition releases (see details in Table 1), we used either remotely download able E obs GPS loggers (www.e obs.de; weight, $28 \mathrm{~g}$; sampling rate, $1 \mathrm{~Hz}$ ) or Fleetronic GSM GPS loggers (www.fleetronic.net; weight, $25 \mathrm{~g}$; sampling rate, one fix every minute from the release site up to $6 \mathrm{~km}$ from home, and one fix every $10 \mathrm{~s}$ in the area within a $6 \mathrm{~km}$ radius around home). The $1 \mathrm{~min}$ sampling rate allowed for longer recording durations (battery life), which enabled us to obtain several complete, post lesion tracks of pigeons that had trouble in navigating home. We changed GPS devices pre lesion and post lesion, because those used after surgery allowed for the remote downloading of data (we only expected to observe failed homing, and consequently failed recovery of the GPS loggers, after HF lesion; therefore, we chose to use the considerably less expen sive GPS loggers without remote download capabilities in the pre lesion condition). The position fixes stored by a GPS data logger included latitude, longitude, speed, and time of recording. The tracks for each pigeon for each recorded release were visualized with Google Earth. Original track data are available on Movebank (movebank.org), and are published in the Movebank Data Reposi tory with DOI 10.5441/001/1.fh860r2f.

\section{Quantitative analyses and statistical procedures}

For the quantitative analyses and based on the data reported in Gag liardo et al. (2007), we considered the "familiar space within the home area' as the area within a $6 \mathrm{~km}$ radius of the home loft. 'Unfa miliar space outside the home area' was any location outside the $6 \mathrm{~km}$ radius. For statistical analysis of each recorded track, regard less of the sampling rate of the GPS, we took one fix every minute and one fix every $10 \mathrm{~s}$ for the portions of the track outside and within the familiar home area, respectively. In other words, regard less of the GPS device used, all tracks were subjected to the same analysis procedures. We excluded from the analysis the fixes recorded when flight speed was $<5 \mathrm{~km} / \mathrm{h}$ and the pigeons were assumed to have landed. For each pigeon in the pre lesion and post lesion conditions, we analysed the following track properties.

\section{Initial orientation and analysis of the tracks outside the home area}

In order to compare the initial orientation of the pigeons before and after HF lesion at the different release sites, we set the home direction to $360^{\circ}$, accumulated the directions taken by a pigeon 
TABLE 1. Details on the Pre and Post lesion releases

\begin{tabular}{|c|c|c|c|c|c|c|c|c|}
\hline Pigeon & RS pre lesion & $\begin{array}{l}\text { Date pre lesion } \\
\text { (day/month/year) }\end{array}$ & RS post lesion & $\begin{array}{l}\text { Date post lesion } \\
\text { (day/month/year) }\end{array}$ & $\begin{array}{l}\text { Tracking } \\
\text { data }\end{array}$ & HS & $\mathrm{DH}$ & GPS \\
\hline 130520 & Bientina & 13/06/2011 & Casciana T & 08/07/2011 & NA & Lost & & E obs \\
\hline 037502 & Bientina & $13 / 06 / 2011$ & Casciana $\mathrm{T}$ & 08/07/2011 & NA & Lost & & E obs \\
\hline 130839 & Bientina & 13/06/2011 & Casciana $\mathrm{T}$ & 08/07/2011 & NA & Lost & 3.0 & E obs \\
\hline 037956 & Bientina & 13/06/2011 & Casciana $\mathrm{T}$ & 08/07/2011 & NA & Lost & & E obs \\
\hline 037712 & Bientina & $13 / 06 / 2011$ & Casciana $\mathrm{T}$ & 08/07/2011 & NA & Lost & & E obs \\
\hline 109132 & Bientina & 13/06/2011 & Casciana $\mathrm{T}$ & 08/07/2011 & $\mathrm{C}^{1,2,3}$ & Homed & & E obs \\
\hline 109287 & Bientina & $13 / 06 / 2011$ & Casciana $\mathrm{T}$ & 08/07/2011 & $C^{1,2,3}$ & Homed & & E obs \\
\hline 095684 & Bientina & 09/08/2012 & Casciana $\mathrm{T}$ & $28 / 08 / 2012$ & I & Homed & & Fleet \\
\hline 095631 & Bientina & $09 / 08 / 2012$ & Casciana $\mathrm{T}$ & $28 / 08 / 2012$ & I & Lost & 11.0 & Fleet \\
\hline 043928 & Bientina & $12 / 08 / 2012$ & Fauglia & 06/09/2012 & NA & Lost & & Fleet \\
\hline 095689 & Bientina & 09/08/2012 & Fauglia & 06/09/2012 & $\mathrm{C}^{1,2,3}$ & Homed & & Fleet \\
\hline 095614 & Bientina & 09/08/2012 & Fauglia & 06/09/2012 & NA & Homed & & Fleet \\
\hline 095683 & Bientina & 09/08/2012 & Fauglia & 07/09/2012 & $\mathrm{I}^{1}$ & Lost & 8.7 & Fleet \\
\hline 137998 & Bientina & $21 / 08 / 2012$ & Fauglia & 07/09/2012 & $\mathrm{I}^{1,2,3 *}$ & Lost & 3.5 & Fleet \\
\hline 096216 & Bientina & $22 / 08 / 2012$ & Fauglia & 07/09/2012 & $\mathrm{C}^{1,2,3}$ & Homed & & Fleet \\
\hline 044211 & Bientina & $22 / 08 / 2012$ & Fauglia & 07/09/2012 & $\mathrm{C}^{1,2,3}$ & Homed & & Fleet \\
\hline 095681 & Bientina & 09/08/2012 & Fauglia & 07/09/2012 & I & Lost & 15.8 & Fleet \\
\hline 095657 & Bientina & 09/08/2012 & Fauglia & 07/09/2012 & I & Lost & 12.4 & Fleet \\
\hline 096271 & Fauglia & $22 / 05 / 2013$ & Tassignano & $11 / 06 / 2013$ & $\mathrm{C}^{1,2,3}$ & Homed & & Fleet \\
\hline 096409 & Fauglia & $22 / 05 / 2013$ & Tassignano & $11 / 06 / 2013$ & I & Homed & & Fleet \\
\hline 096242 & Fauglia & $22 / 05 / 2013$ & Tassignano & $11 / 06 / 2013$ & $\mathrm{I}^{1}$ & Lost & 9.8 & Fleet \\
\hline 096218 & Fauglia & $22 / 05 / 2013$ & Tassignano & $11 / 06 / 2013$ & $C^{1,2,3}$ & Homed & & Fleet \\
\hline 096233 & Fauglia & $22 / 05 / 2013$ & Tassignano & $11 / 06 / 2013$ & $C^{1,2,3}$ & Homed & & Fleet \\
\hline 096414 & Fauglia & $22 / 05 / 2013$ & Tassignano & $11 / 06 / 2013$ & $\mathrm{I}^{1}$ & Homed & & Fleet \\
\hline 096265 & Fauglia & $22 / 05 / 2013$ & Tassignano & $11 / 06 / 2013$ & I & Lost & 24.1 & Fleet \\
\hline 137956 & Fauglia & $22 / 05 / 2013$ & Tassignano & $11 / 06 / 2013$ & $\mathrm{I}^{1}$ & Lost & 33.0 & Fleet \\
\hline 044214 & Tassignano & $21 / 05 / 2013$ & Fauglia & $12 / 06 / 2013$ & $\mathrm{I}^{1,2}$ & Lost & 5.8 & Fleet \\
\hline 043903 & Tassignano & $21 / 05 / 2013$ & Fauglia & $12 / 06 / 2013$ & $\mathrm{C}^{1,2,3}$ & Homed & & Fleet \\
\hline 043910 & Tassignano & $21 / 05 / 2013$ & Fauglia & $12 / 06 / 2013$ & $C^{1,2,3}$ & Homed & & Fleet \\
\hline 043917 & Tassignano & $21 / 05 / 2013$ & Fauglia & $12 / 06 / 2013$ & NA & Homed & & Fleet \\
\hline 096248 & Tassignano & $21 / 05 / 2013$ & Fauglia & $12 / 06 / 2013$ & NA & Lost & & Fleet \\
\hline 043921 & Tassignano & $21 / 05 / 2013$ & Fauglia & $12 / 06 / 2013$ & $C^{1,2,3}$ & Homed & & Fleet \\
\hline 044218 & Tassignano & $21 / 05 / 2013$ & Fauglia & $12 / 06 / 2013$ & $\mathrm{I}^{1}$ & Lost & 10.3 & Fleet \\
\hline
\end{tabular}

$\mathrm{C}$, complete track from the release site to at least $1 \mathrm{~km}$ from home; Date post lesion, date of release test in the post lesion condition; Date pre lesion, date of release test in the pre lesion condition; DH, distance $(\mathrm{km})$ from home of the last fix recorded for the pigeons lost during the post lesion test; E obs, E obs GPS loggers; Fleet, Fleetronic GSM GPS loggers; GPS, type of device used in the post lesion condition; HS, homing success; I, incomplete track; NA, data not available; RS post lesion, release site in the post lesion condition; RS pre lesion, release site in the pre lesion condition. The superscript numbers indicate the parameters included in the analysis, as follows: ${ }^{1}$ mean vector length relative to the section of track up to $10 \mathrm{~km}$ distant from the release site; ${ }^{2}$ mean vector length and efficiency index outside the home area, ${ }^{3}$ mean vector length and EI inside the home area. *The data inside the home area are available only in the range of $63 \mathrm{~km}$ from the loft.

moving from one point to the next (sampled every minute), and calculated the mean vector. For this analysis, we excluded the first portion of the track from the release site to a distance of $1 \mathrm{~km}$, the distance over which the flight path is often characterized by lots of circling. This analysis was applied to the portion of the tracks ranging from 1 to $10 \mathrm{~km}$ from the release point. For the pigeons that reached the home area in the post lesion condition, the same procedure was additionally applied to the whole track up to the home area. The resulting mean vector gives a good description of the consistency of the flight path direction during the initial homing phase. The mean vectors were tested for randomness with a one sample Hotelling test (Batschelet, 1981). The pre lesion and post lesion mean direction distributions were compared by use of a Hotelling test for paired data. The mean vector lengths and the angular deviations from the home direction were compared by use of a paired sample $t$ test and the Wilcoxon paired sample test (Zar, 1984), respectively.

As a supplemental analysis, we also calculated the efficiency index (EI) for the portion of the track outside the home area as defined above. The EI is calculated by dividing the beeline (shortest) distance between the first point of a track at $1 \mathrm{~km}$ from the release site and the point at which a pigeon crosses the home area boundary by the length of the actual, recorded track to the same point at the familiar area boundary. The EI scores pre lesion and post lesion were compared by use of a paired sample $t$ test.

\section{Analysis of tracks within the home area}

To analyse track tortuosity within the entire home area, we accumu lated the directions taken by a pigeon moving from one point to the next (now sampled every $10 \mathrm{~s}$ ) and calculated the mean vector. The mean vector lengths derived from the $10 \mathrm{~s}$ sampling are representa tive of a flight path's tortuosity. A paired sample $t$ test was applied to the mean vector lengths of the pre lesion and post lesion condi tions.

To analyse tortuosity per kilometre, we drew concentric circles around home at $1 \mathrm{~km}$ intervals, from 1 to $6 \mathrm{~km}$, and separately anal ysed the portions of the tracks included in a ring delimited by two consecutive circles [see Gagliardo et al. (2011a,b) for details]. For each $1 \mathrm{~km}$ segment, we accumulated the directions taken by a pigeon moving from one fix to the next, and calculated the mean vector. For the pre lesion and post lesion conditions, the tortuosity of the flight paths when the pigeons first entered the home area (from 6 to $5 \mathrm{~km}$ from the loft) was compared with the same mea 
sure recorded closer to the home loft (from 2 to $1 \mathrm{~km}$ from the loft) by applying a paired sample $t$ test to the mean vector lengths. A Spearman correlation test was applied to the difference in tortuosity (mean vector lengths) between the pre lesion and post lesion condi tions at increasing distances from home up to $6 \mathrm{~km}$, in order to fur ther assess whether the difference in flight path tortuosity varied with the distance from home.

Again, as a supplemental analysis, we calculated the EIs of the portions of the tracks within the home area. The EI was calculated by dividing the beeline (shortest) distance between the first point at which a pigeon crossed the home area boundary to the home loft (or, for one pigeon, when lesioned to the end of its track) by the length of the actual, recorded track inside the home area. The home area EIs pre lesion and post lesion were compared by use of a paired sample $t$ test.

\section{Homing performance}

The homing success (number of pigeons homed) of the pigeons post lesion was also recorded. A comparison with the pre lesion homing success was performed with a McNemar test (Zar, 1984). However, because the GPSs used in the post lesion condition were, in many cases, able to remotely transmit data from pigeons that did not return to the home loft, we were able to report the dis tance from home of their last recorded fix. This enabled us to per form an analysis of the in flight, instantaneous speed (provided by the GPS) of the pigeons for the portion of a track ranging across $110 \mathrm{~km}$ from the release site. Additionally, for the pigeons for which we had flight recordings within the home area, we analysed the average speed (distance covered between two points divided by the time employed to go from the first point to the second), both outside and inside the home area independently. For the tracks recorded outside and within the area of familiarity, the instantaneous and average speeds of the pigeons pre lesion and post lesion were compared by use of a paired sample $t$ test or Wilcoxon test.

\section{Histology and lesion reconstruction}

To assess the extent of lesion damage, 13 of the HF lesioned pigeons were killed for histology (reconstructions were not carried out for pigeons that did not return to the home loft or were lost in the interval between the completion of the current study and the time of perfusion). The pigeons were deeply anaesthetized with an overdose of a $20 \%$ solution of chloral hydrate, and perfused intra cardially with $10 \%$ formalin. Once extracted, the brains were cut coronally, in $40 \mu \mathrm{m}$ sections, with a freezing sliding microtome. The sections were stained with cresyl violet, and, with the aid of a macroprojector, the lesions were reconstructed on standard coronal sections derived from the pigeon brain atlas (Karten \& Hodos, 1967).

\section{Results}

As a consequence of GPS malfunction or loss, for nine of the 33 pigeons in the post lesion condition, no data were available for any of the analyses carried out. Six pigeons were inactive for several hours after the release, so that the tracks were too short $(14 \mathrm{~km})$ for any analysis. Thus, we obtained data from 11 complete and seven incomplete post lesion tracks of different lengths for which we were able to carry out at least some of the analyses described in Materials and methods (see Table 1 for details).
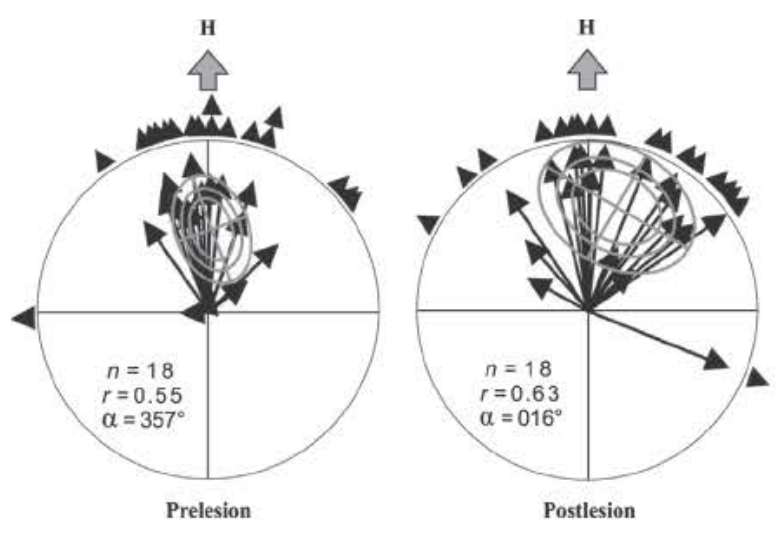

FIG. 1. Mean vector distributions in the pre lesion and post lesion condi tions, with the home direction set at $360^{\circ}$. Each mean vector indicates the mean orientation of a pigeon's track ranging over $110 \mathrm{~km}$ of unfamiliar space from the release point. The mean vector distributions were tested for randomness with the Hotelling test $(95,99$ and $99.9 \%$ confidence ellipses are shown). Triangles outside the periphery of the circles represent the vectors' mean directions. $r$, second order mean vector length; $\alpha$, direction.

TABLE 2. Initial orientation $110 \mathrm{~km}$ from the release site

\begin{tabular}{|c|c|c|c|c|}
\hline \multirow[b]{2}{*}{ Pigeon } & \multicolumn{2}{|c|}{ Pre lesion } & \multicolumn{2}{|c|}{ Post lesion } \\
\hline & $r$ & $\alpha$ & $r$ & $\alpha$ \\
\hline 109132 & 0.73 & 006 & 0.90 & 037 \\
\hline 109287 & 0.61 & 019 & 0.94 & 033 \\
\hline 095689 & 0.92 & 354 & 0.84 & 001 \\
\hline 095683 & 0.76 & 001 & 0.81 & 051 \\
\hline 137998 & 0.70 & 344 & 0.84 & 326 \\
\hline 096216 & 0.64 & 347 & 0.40 & 025 \\
\hline 044211 & 0.64 & 325 & 0.96 & 006 \\
\hline 096271 & 0.76 & 339 & 0.78 & 045 \\
\hline 096242 & 0.15 & 268 & 0.40 & 299 \\
\hline 096218 & 0.85 & 342 & 0.96 & 022 \\
\hline 096233 & 0.66 & 349 & 0.35 & 049 \\
\hline 096414 & 0.27 & 050 & 0.54 & 318 \\
\hline 137956 & 0.56 & 046 & 0.88 & 112 \\
\hline 044214 & 0.11 & 014 & 0.96 & 355 \\
\hline 043903 & 0.79 & 001 & 0.91 & 346 \\
\hline 043910 & 0.11 & 052 & 0.80 & 352 \\
\hline 043921 & 0.60 & 019 & 0.96 & 357 \\
\hline 044218 & 0.75 & 357 & 0.96 & 022 \\
\hline
\end{tabular}

The mean vectors are calculated from the directions taken by a pigeon when moving from a fix to the next. Sampling rate considered for the analysis: one fix per minute. $r$, mean vector length; $\alpha$, direction.

\section{Initial orientation and analysis of the tracks outside the home area}

The individual mean vector, pre lesion and post lesion distributions for the portion of the tracks ranging from 1 to $10 \mathrm{~km}$ from the release site, representing the consistency in direction (or straightness of the flight path), are reported in Fig. 1 (see also Table 2). Both the pre lesion and post lesion mean vector distributions were signifi cantly different from random according to the one sample Hotelling test ( $n$ 18; pre lesion, second order mean vector length and direc tion, $r \quad 0.55, \propto 357^{\circ}, \mathrm{T} 2 \quad 72.06, P<0.001$; post lesion, $\left.r \quad 0.63, \alpha \quad 016^{\circ}, \mathrm{T} 2 \quad 75.57, P<0.001\right)$. In both cases, the $95 \%$ confidence limits of the mean vector distributions included the home direction (pre lesion, $334044^{\circ}$; post lesion, $335062^{\circ}$ ). However, the two distributions turned out to be significantly different accord ing to the Hotelling test for paired data ( $n$ 18, $F$ 3.70, 


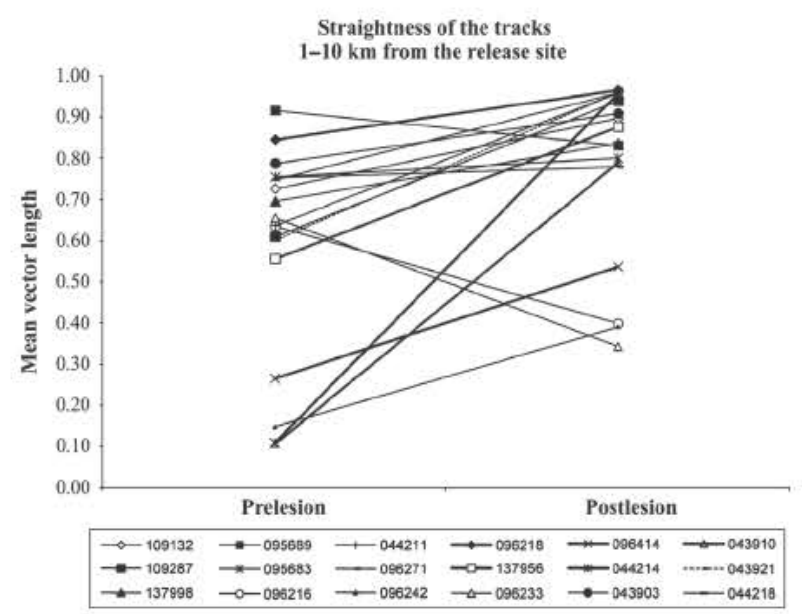

FIG. 2. Individual mean vector lengths $\left(\begin{array}{ll}n & 18\end{array}\right)$ calculated from angles sam pled every $1 \mathrm{~min}$, indicating the straightness of the flight path recorded between 1 and $10 \mathrm{~km}$ from the release point, pre lesion and post lesion. Greater vector lengths indicate greater straightness.

$P<0.05$ ). This difference was a result of a significant increase (Figs 1 and 2) in the mean vector length pre lesion (paired sample $t$ test applied to the pre lesion and post lesion mean vector length, $P \quad 0.004$ ), and not to a difference in direction (Wilcoxon paired sample test applied to the angular deviation from the home direc tion, $P>0.1$ ). The data indicate that the pigeons, after having had their HFs lesioned, actually flew a straighter homeward path during the part of the homing flight over unfamiliar terrain.

Although it was not significant, the increase in mean vector length in the post lesion condition also occurred when we consid ered the subset of tracks for which we obtained tracking data all the way to the beginning of the home area (analysis from $1 \mathrm{~km}$ from the release point up to the beginning of the home area: $n$ 13; first order mean of the vector length; pre lesion, $0.56 \pm 0.21$, post lesion, $0.67 \pm 0.20$; paired sample $t$ test, $P \quad 0.09$ ). Again, this last analysis reinforces the conclusion that, when homing over unfamiliar areas and homeward oriented, pigeons without an HF actually fly straighter paths.

Consistent with the above analysis and conclusion, the EI scores revealed more direct navigation to the home area post lesion (Fig. 3a; $n$ 13; pre lesion mean EI $0.59 \pm 0.21$; post lesion mean EI $\quad 0.72 \pm 0.18$; paired sample $t$ test, $P \quad 0.05$ ).

\section{Analysis of tracks within the home area}

In contrast to the flight paths recorded over unfamiliar space (above), the individual mean vector lengths of the tracks within the home area ( $6 \mathrm{~km}$ radius) were, as expected, significantly shorter post lesion ( $n$ 12; a pigeon that did not return home but with a track interrupted $3.5 \mathrm{~km}$ from its loft was also included in this analysis; paired sample $t$ test, $P \quad 0.03$; Fig. 4). As this analysis was conducted on fixes sampled every $10 \mathrm{~s}$, the resolution was high enough to detect small loops in flight paths and frequent changes in direction. For this reason, the mean vectors lengths for this analysis represent a good index of the tortuosity of the tracks. Therefore, in the post lesion condition, the pigeons were more likely to fly a more tortuous path within the home area. In addition, the analysis of individual mean vector lengths conducted every kilometre from the border of the home area up to $1 \mathrm{~km}$ from the loft (mean vector length per kilometre; Fig. 5) revealed that, in the post lesion condi tion, the pigeons' flight paths became increasingly more tortuous the
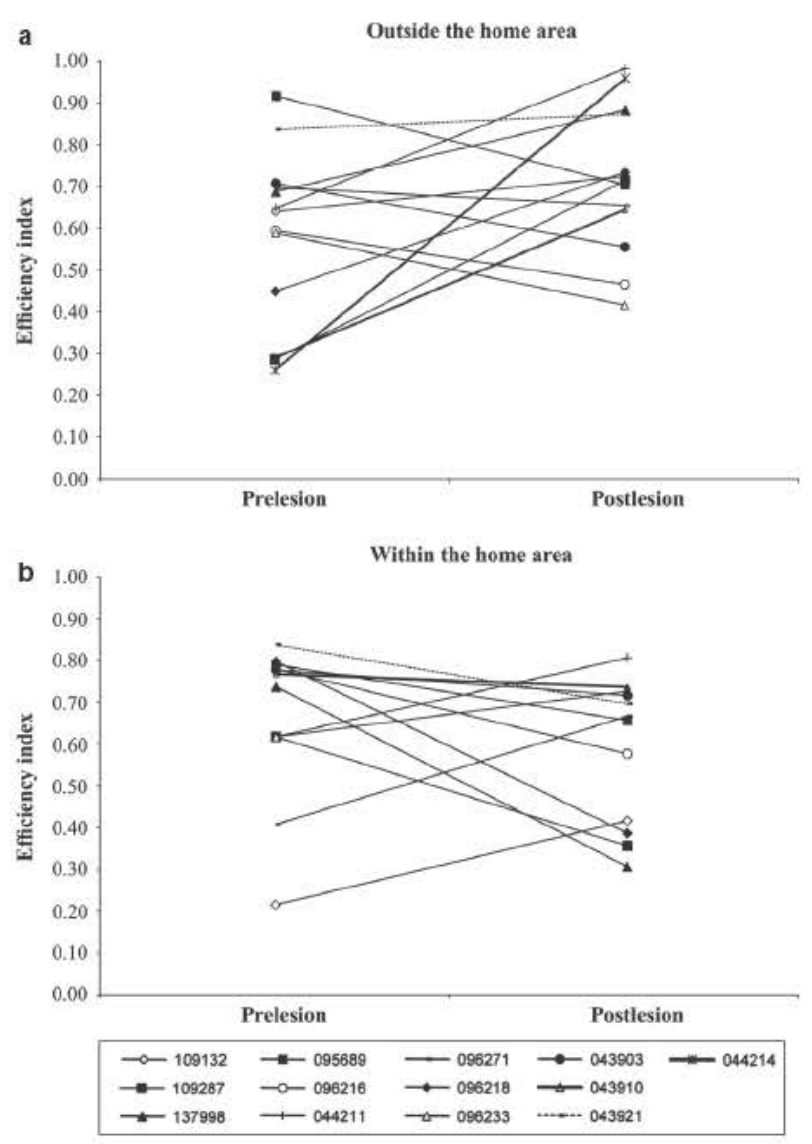

FIG. 3. Individual EI values of the portions of the tracks outside (a, $n$ and inside $(b, n 12)$ the home area.

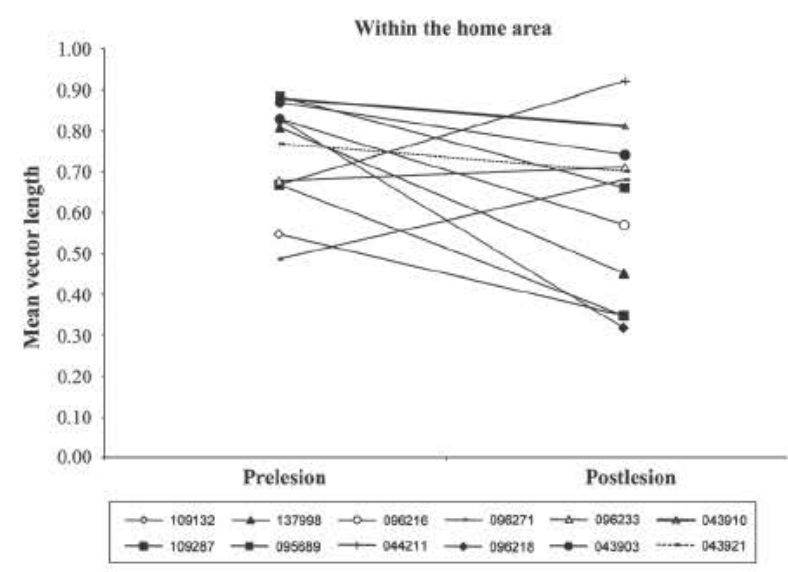

FIG. 4. Individual mean vector lengths ( $n$ 12) calculated from angles sam pled every $10 \mathrm{~s}$, indicating the tortuosity of the flight path recorded within the home area, pre lesion and post lesion. Greater vector lengths indicate smaller tortuosity and fewer loops.

closer they approached the home loft (Spearman correlation test, $n \quad 58$, Spearman $r \quad 0.317, P<0.02$ ). In fact, in the pre lesion condition, the pigeons maintained the same level of flight path tortu osity during the portion of the track ranging between 6 and $5 \mathrm{~km}$ from the loft and the portion of the track in the vicinity of the loft (pre lesion condition: 6 to $5 \mathrm{~km}$ mean of the mean vector lengths, $0.85 \pm 0.06 ; 2$ to $1 \mathrm{~km}$ mean of the mean vector lengths, $0.90 \pm 0.04$; paired sample $t$ test, $P \quad 0.17$ ). In contrast, a signifi cant difference emerged when the same comparison was applied to 


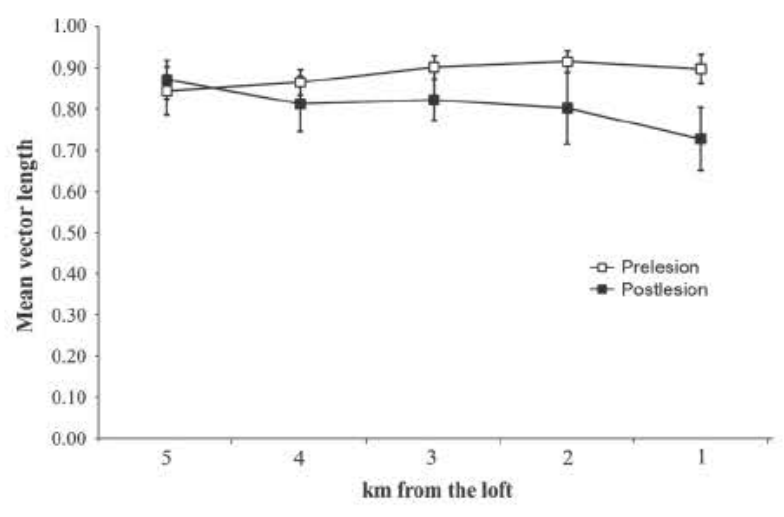

FIG. 5. Mean group tortuosity within the home area at distances ranging from $\mathrm{km} 65$ (5) to $\mathrm{km} 21$ (1) from the loft. The error bars represent the standard errors.

the post lesion condition (post lesion condition: 5 to $6 \mathrm{~km}$ mean of the mean vector lengths, $0.87 \pm 0.05 ; 2$ to $1 \mathrm{~km}$ mean of the mean vector lengths, $0.73 \pm 0.08$; paired sample $t$ test, $P<0.05$ ). The increased tortuosity within the home area post lesion is illustrated in the flight paths shown in Fig. 6d and e. Finally, and as expected, the familiar area EI recorded pre lesion was now higher than the EI recorded post lesion, but the difference failed to reach statistical significance (Fig. 3b; $n$ 12; pre lesion mean EI $0.68 \pm 0.19$; post lesion mean EI $\quad 0.59 \pm 0.17$; paired sample $t$ test, $P \quad 0.14$ ).

\section{Homing performance}

Approximately half of the pigeons released in the post lesion condi tion failed to navigate back to the home loft (17 of 33 pigeons released; Table 1). The McNemar test revealed that a significantly smaller percentage of pigeons returned to the loft post lesion than pre lesion $(P<0.001)$. Such an effect is consistent with the tracks shown in Fig. 6, revealing that, although post lesion most pigeons were homeward directed following release, the number of lost pigeons increased as they approached the home loft, where hippo campal involvement in navigation became increasingly important. In fact, remotely downloaded tracking data and one recovery (one pigeon was found predated $4 \mathrm{~km}$ from home) showed that at least three of the pigeons actually reached the home area and another five lost pigeons approached home to a variable extent (Fig. 6; Table 1). Three of these five approached to more than half of the initial dis tance from home $(66,54$, and $53 \%)$, and the last recorded fix of the other two showed that they covered almost half of the distance from home (the approach distances expressed as percentages of the initial distance from home were 46 and $35 \%$ ). For the other three 'lost' pigeons reported in Fig. 6, the last fix recorded was either near the release site or at a greater distance from home. What is interesting about the recovery data is that, even if their flight paths were bring ing them closer to the home loft, some of the pigeons post lesion were unable to complete the navigational challenge upon approach ing that portion of the journey home where familiar landmarks and landscape features were becoming increasingly important.

The analysis of average homing speed revealed that the pigeons were slower at homing post lesion than pre lesion. This was true both outside ( $n$ 12; median average speed pre lesion, $6.8 \mathrm{~km} / \mathrm{h}$; median average speed post lesion, $1.1 \mathrm{~km} / \mathrm{h}$; Wilcoxon test, $P<0.01$ ) and within ( $n$ 12; median average speed pre lesion, $39.8 \mathrm{~km} / \mathrm{h}$; median average speed post lesion, $17.9 \mathrm{~km} / \mathrm{h}$; Wilcoxon test, $P<0.05)$ the familiar home area. We interpret lower homing speeds in the post lesion condition to be navigation related, because, post lesion, the pigeons were more likely to land or stop overnight before reaching the home loft ( $n$ 14; mean time 'landed' outside the home area pre lesion, $4^{\mathrm{h}} 19^{\prime} 30^{\prime \prime} \pm 4^{\mathrm{h}} 48^{\prime} 42^{\prime \prime}$; mean time 'landed' outside the home area post lesion, $14^{\mathrm{h}} 51^{\prime} 24^{\prime \prime} \pm 8^{\mathrm{h}} 09^{\prime} 56^{\prime \prime}$; paired $t$ test, $P<0.005)$ (n 13, mean time 'landed' within the home area pre lesion, $0^{\mathrm{h}} 08^{\prime} 54^{\prime \prime} \pm 0^{\mathrm{h}} 19^{\prime} 27^{\prime \prime}$; mean time 'landed' within the home area post lesion, $3^{\mathrm{h}} 20^{\prime} 22^{\prime \prime} \pm 6^{\mathrm{h}} 47^{\prime} 43^{\prime \prime} ; P \quad 0.057$ ). Of more importance, the instantaneous speed of the pigeons in flight was not different pre lesion and post lesion. Both for the unfamiliar, initial portion of the homing flight ( $110 \mathrm{~km}$ from the release site; $n \quad 20$; median instantaneous speed pre lesion, $54.0 \mathrm{~km} / \mathrm{h}$; median instanta neous speed post lesion, $56.0 \mathrm{~km} / \mathrm{h}$; Wilcoxon test, $P>0.5$ ) and within the familiar, home area $(n \quad 12$; median instantaneous speed pre lesion, $49.1 \mathrm{~km} / \mathrm{h}$; median instantaneous speed post lesion, $51.5 \mathrm{~km} / \mathrm{h}$; Wilcoxon test, $P>0.5$ ), the pigeons, when flying, were equally fast pre lesion and post lesion.

\section{Lesion reconstruction}

In the 13 sampled HF lesioned pigeons, the substantial damage to both the hippocampus and parahippocampus subdivisions of the HF was somewhat variable across the subjects (Fig. 7). For all pigeons, sparing was primarily limited to the most anterior portions of the hippocampus and parahippocampus. In some birds, the lesions extended modestly into either the hyperpallium apicale, hyperpallium densocellulare, mesopallium, or nidopallium (Reiner et al., 2004).

\section{Discussion}

The canonical view of pigeon homing from unfamiliar locations is that, when a pigeon is released, it first samples navigational factors such as atmospheric odours at the release site (Papi, 1990; Wallraff, 2005; Gagliardo, 2013) to determine its location relative to home (the map step or navigational map), and then transforms the posi tional information into a homeward direction (the compass step) by using the sun or the earth's magnetic field (Schmidt Koenig, 1960; Wiltschko \& Wiltschko, 2003). Once a pigeon's flight brings it over familiar territory, it gradually becomes less reliant on its naviga tional map, and becomes increasingly reliant on familiar landmarks and landscape features to navigate to the home loft (Wallraff \& Neumann, 1989; Wallraff, 1991; Holland, 2003; Biro et al., 2004; Gagliardo et al., 2007).

The first experiments examining the role of the avian HF in pigeon homing were performed in the $1980 \mathrm{~s}$ (Bingman et al., 1984), and numerous studies since then (e.g. Gagliardo et al., 2009) [see Bingman et al. (2005) for a review] have led to the conclusion that the HF is crucial for map like navigation based on familiar landmarks and landscape features, but, because of vanishing bearing data, plays no role in the operation of the navigational map that guides homing from distant, unfamiliar locations. The results of the current study based on the GPS tracking of homing flights from unfamiliar sites supports the previous studies in demonstrating that HF lesioned pigeons are able to establish their position with respect to home and to orient towards the goal at unfamiliar release sites (Bingman et al., 1984), but show less directed flight paths and gen erally impoverished navigation in the familiar space near the home loft (Bingman et al., 1984, 1988; Bingman \& Mench, 1990). This view is usually used to explain why, following HF lesions, homing pigeons have such a difficult time in returning to the home loft. In the current study, we interpret the substantial losses observed following HF lesion to be primarily a consequence of the pigeons 

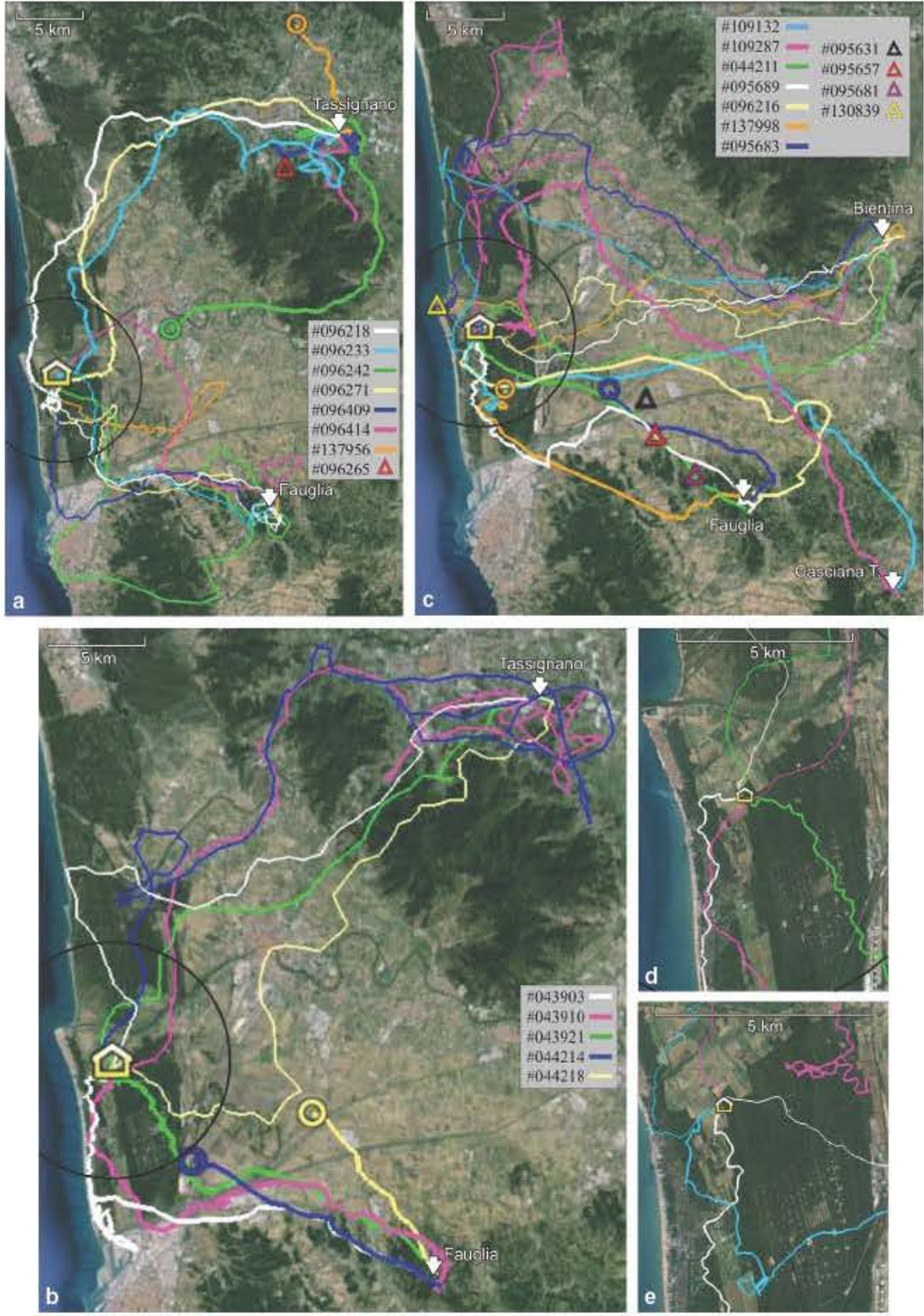

FIG. 6. Pigeon tracks in the pre lesion (thin lines) and post lesion (thick lines) conditions. Lines of the same colour in each panel represent the tracks of the same individual. Small coloured triangles and circles represent the last recorded positions of pigeons that did not home after being released in the post lesion condition. The associated paths of the circle positions were included in at least some of the analyses (see Table 1 for details); triangle positions were not accom panied by any track data. The interrupted tracks not associated with a circle are those of pigeons that, when lesioned, eventually homed. The house symbol rep resents the home loft. The $6 \mathrm{~km}$ radius around the home area is delimited by the black circle. (a) Pre lesion and post lesion release sites Fauglia and Tassignano. (b) Pre lesion and post lesion release sites Tassignano and Fauglia. (c) Pre lesion release site Bientina and post lesion release sites Fauglia and Cas ciana Terme. (d) Zoomed image of the tracks of three pigeons in the home area in (b). (e) Zoomed image of the tracks of three pigeons in the home area in (c).

unsuccessfully navigating once reaching the familiar area near the home loft, where their intact navigational map and compass mecha nisms lack the spatial resolution to guide them home.

The unexpected finding of the current study, which could only have been obtained with GPS tracking, is that, even over distant, unfamiliar space, HF lesions impact on the homing paths of pigeons. Also, surprisingly, the data of the current study show that HF lesioned pigeons fly straighter paths towards home when navigating over unfamiliar space.

But what does 'flying straighter' over unfamiliar space mean in the context of how the HF contributes to avian spatial cognition? It is well known that when pigeons are flying home their paths often deviate from straight, being influenced by surface topographic fea tures (Wagner, 1972; Wallraff, 1994; Lipp et al., 2004). Peculiar familiar landscape features experienced in the home area, e.g. human settlements, have been shown to exert an attraction even at unfamiliar locations (Wallraff, 1994). It may be that such deviations from a straight path home reflect a kind of exploration, which could support learning of the spatial relationships among topographic fea tures that would aid navigation on subsequent flights. The findings reported in Patzke et al. (2010) are consistent with this explanation. They observed increased ZENK expression in the HF, not only in 


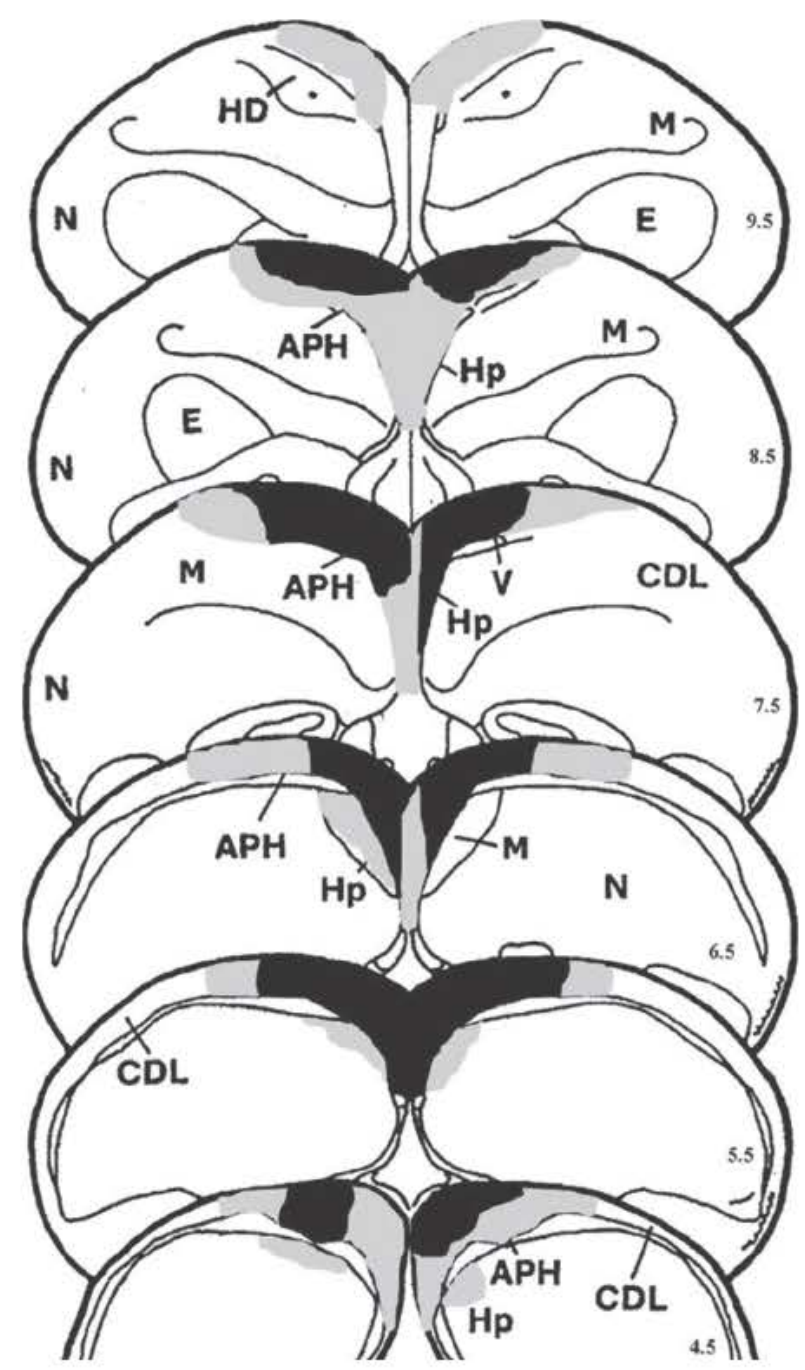

FIG. 7. Summary lesion reconstruction of the 11 sampled HF lesioned pigeons. Black areas represent regions of brain damage common to at least nine of the 11 pigeons; grey areas represent regions of brain damage com mon to at least four of the 11 pigeons. Numbers on the right indicate ante rior posterior coordinates of the sections (Karten \& Hodos, 1967). Abbreviations (from Reiner et al. (2004): APH, parahippocampus; CDL, cor ticoid; E, entopallium; HD, hyperpallium densocellulare; $\mathrm{Hp}$, hyperpallium apicale; M, mesopallium; $\mathrm{N}$, nidopallium; V, ventricle.

pigeons released in the vicinity of the home loft, but also in pigeons released at an unfamiliar location. The activation of hippocampal neurones during the homing flight over unfamiliar areas, in our view, probably reflects learning processes related to local topogra phy as a source of spatial information. We propose that homing pigeons without an HF fly straighter paths home because they attend less to topographic features, and, by analogy, fly on a kind of 'auto pilot' that is reliant almost entirely on their navigational map and compass. If this is true, the role of the HF in spatial cognition would go beyond memory, and would include necessary participation in attending to and identifying salient topographic features. Damage to the HF would then result in a kind of pre mnemonic, perceptual neglect of such topographic features, with an associated decline in spatial memory, including map formation. Consistent with this working hypothesis is that HF lesioned pigeons are more reliant on their sun compass when homing from familiar locations (Gagliardo et al., 1999), and, when GPS tracked over familiar space, routinely ignore the conspicuous landscape boundary of the Mediterranean coast (Gagliardo et al., 2009). The implication of this line of think ing is that the relationship between the HF and space is not restricted to memory, but includes an unanticipated 'directed guid ance' to attend to environmental features, which could presumably assist navigation on subsequent homing flights.

However, we recognize that the hypothesized perceptual neglect described above may not completely explain the observation of straighter paths over unfamiliar terrain, even though the EI analysis showed that HF lesions did, in fact, result in straighter paths home. It could be argued, for example, that HF lesions had a non specific effect on anxiety or stereotypical behavioural tendencies, as reported in rodents (e.g. Deacon \& Rawlins, 2005). However, in our view, the conflicting observation of more direct homing over unfamiliar space and more circuitous flight behaviour near the home loft is not easily explained by such non specific effects; if HF lesions increase the propensity for stereotypical flight behaviour, why would that have different navigational consequences if a pigeon was over unfa miliar or familiar space? Also, the 'better performance' over unfa miliar space reported here is in agreement with the finding that HF lesions can improve performance on even laboratory goal location tasks (e.g. Vargas et al., 2004). Vargas et al. (2004) reported that $\mathrm{HF}$ lesioned pigeons learned faster than intact pigeons to locate food contained in one of four feeders placed at each comer of a rectangu lar arena with a polarizing cue on one wall. Interestingly, the HF lesioned pigeons were subsequently impaired when tested after removal of the polarizing cue, in other words, when they had to exclusively rely on the boundary geometry of the arena to locate the goal corner. The authors proposed that the HF lesioned pigeons learned the task faster because they relied solely on the polarizing cue, and did not learn in parallel the goal location based on bound ary geometry. Returning to the current study, we believe that our hypothesis of a kind of perceptual neglect best explains the observed behaviour after HF lesion, but acknowledge that other factors may contribute to the effect, and the need for further experiments to fully test the hypothesis.

In general, the current study supports the recognized role of the HF in navigation over familiar space in the vicinity of the home loft, but even here the GPS tracks reveal some nuances in the behaviour of HF lesioned pigeons that offer new insights into what homing without a hippocampus may be like. The re location of numerous pigeons that did not home following HF lesion hints that the navigational map and compass can only bring pigeons close to the home loft (see also below), and if the map and compass do not bring pigeons in sight of the home loft, where the loft can serve as an attractor beacon, then such pigeons may never return. The data also suggest that the operational range of the map and compass may be highly variable across individuals.

It is also noteworthy that we were able to observe a general decrease in navigational efficiency as the pigeons, when HF lesioned, approached the home loft even within the boundaries of our defined familiar space. What this suggests again is that, even over familiar space, navigational map and compass mechanisms can enable homing pigeons to approach the home loft, although in a less efficient way than when they are using familiar landmarks, and, for many pigeons, only during the very last stages of the homing flight is navigation entirely dependent on familiar environmental features (Wallraff, 1991; Gagliardo et al., 2007).

In summary, the use of GPS tracking technology has enabled a revolution in navigation research, including the expanded possibility of studying brain mechanisms that guide navigation in the field. The results of the current study reveal a larger role of the avian HF in 
pigeon homing than previously recognized, including an unexpected involvement over space unfamiliar to the pigeons. In our opinion, the active involvement of the avian HF during navigation from unfa miliar locations reflects participation in the perceptual arbitration of what aspects of the environment could be incorporated in construct ing memory representations of space. The possibility that the HF influences how animals sample/attend to space forces one to view the HF as being more than passively involved in the assimilation of spatial experiences into memory; it seems to be involved in also determining what spatial experiences are had. From a comparative perspective, it now becomes of particular interest to determine whether a 'hippocampus beyond the boundaries of memory' might also characterize the hippocampus of other vertebrate groups and even humans (Kaplan et al., 2014), as well reviving many of the seminal ideas of O'Keefe \& Nadel (1978).

\section{Acknowledgements}

We wish to thank Fabio Chini, Andrea Guidi and Caterina Filannino for their help with the experiments, and Daniele Santerini for preparation of the fig ures.

\section{Abbreviations}

EI, efficiency index; HF, hippocampal formation.

\section{References}

Batschelet, E. (1981) Circular Statistics in Biology. Academic Press, Lon don.

Bingman, V.P. \& Mench, J.A. (1990) Homing behavior of hippocampus and parahippocampus lesioned pigeons following short distance releases. Behav. Brain Res., 40, 227238.

Bingman, V.P., Bagnoli, P., Ioalè, P. \& Casini, G. (1984) Homing behavior of pigeons after telencephalic ablations. Brain Behav. Evolut., 24, 94108.

Bingman, V.P., Ioalè, P., Casini, G. \& Bagnoli, P. (1988) Hippocampal ablated homing pigeons show a persistent impairment in the time taken to return home. J. Comp. Physiol. A., 163, 559563.

Bingman, V.P., Hough, I.I., Kahn, M.C. \& Siegel, J.J. (2003) The homing pigeon hippocampus and space: in search of adaptive specialization. Brain Behav. Evolut., 62, 117127.

Bingman, V.P., Gagliardo, A., Hough, G.E., Ioalé, P., Kahn, M.C. \& Siegel, J.J. (2005) The avian hippocampus, homing in pigeons and the memory representation of large scale space. Integr. Comp. Biol., 45, 555564.

Biro, D., Meade, J. \& Guilford, T. (2004) Familiar route loyalty implies visual pilotage in the homing pigeons. Proc. Natl. Acad. Sci. USA, 101, 1744017443.

Colombo, M. \& Broadbent, N. (2000) Is the avian hippocampus a functional homologue of the mammalian hippocampus? Neurosci. Biobehav. R., 24, 465484.

Deacon, R.M.J. \& Rawlins, J.N.P. (2005) Hippocampal lesions, species typical behaviours and anxiety in mice. Behav. Brain Res., 156, 241249.

Gagliardo, A. (2013) Forty years of olfactory navigation in birds. J. Exp. Biol., 216, 21652171.

Gagliardo, A., Ioalè, P. \& Bingman, V.P. (1999) Homing in pigeons: the role of the hippocampal formation in the representation of landmarks used for navigation. J. Neurosci., 19, 311315.

Gagliardo, A., Ioalè, P., Savini, M., Lipp, H. P. \& Dell’Omo, G. (2007) Finding home: the final step of the pigeons' homing process studied with a GPS data logger. J. Exp. Biol., 210, 11321138.

Gagliardo, A., Ioalè, P., Savini, M., Dell'Omo, G. \& Bingman, V.P. (2009) Hippocampal dependent familiar area map support corrective re orientation following navigational error during pigeon homing: a GPS tracking study. Eur. J. Neurosci., 29, 23892400.
Gagliardo, A., Filannino, C., Ioalè, P., Pecchia, T., Wikelski, M. \& Vallortig ara, G. (2011a) Olfactory lateralization in homing pigeons: a GPS study on birds released with unilateral olfactory inputs. J. Exp. Biol., 214, 593598.

Gagliardo, A., Ioalè, P., Filannino, C. \& Wikelski, M. (2011b) Homing pigeons only navigate in air with intact environmental odours: a test of the olfactory activation hypothesis with GPS data loggers. PLoS One, 6, e22385.

Guilford, T., Åkesson, S., Gagliardo, A., Holland, R.A., Mouritsen, H., Mu heim, R., Wiltschko, R., Wiltschko, W. \& Bingman, V.P. (2011) Migra tory navigation in birds: new opportunities in an era of fast developing tracking technology. J. Exp. Biol., 214, 37053712.

Hampton, R.R. \& Shettleworth, S.J. (1996) Hippocampal lesions impair memory for location but not color in passerine birds. Behav. Neurosci., 110, 831835.

Holland, R.A. (2003) The role of visual landmarks in the avian familiar area map. J. Exp. Biol., 206, 17731778.

Kaplan, R., Horner, A.J., Bandettini, P.A., Doeller, C.F. \& Burgess, N. (2014) Human hippocampal processing of environmental novelty during spatial navigation. Hippocampus, 24, 740750.

Karten, H. \& Hodos, W. (1967) A Stereotaxic Atlas of the Brain of the Pigeon (Columba livia). John Hopkins, Baltimore, MD.

Lipp, H. P., Vyssotski, A.L., Wolfer, D.P., Renaudineau, S., Savini, M., Troster, G. \& Dell'Omo, G. (2004) Pigeon homing along highways and exits. Curr. Biol., 14, 12391249.

Mayer, U., Watanabe, S. \& Bischof, H.J. (2009) Hippocampal activation of immediate early genes Zenk and c Fos in zebra finches (Taeniopygia gut tata) during learning and recall of a spatial memory task. Neurobiol. Learn. Mem., 93, 322329.

O'Keefe, J. \& Nadel, L. (1978) The Hippocampus as a Cognitive Map. Oxford University Press, Oxford.

Papi, F. (1990) Olfactory navigation in birds. Experientia, 46, 352363.

Patzke, N., Manns, M., Gunturkun, O., Ioalè, P. \& Gagliardo, A. (2010) Navigation induced ZENK expression in the olfactory system of pigeons (Columba livia). Eur. J. Neurosci., 31, 20622072.

Reiner, A., Perkel, D.J., Bruce, L.L., Butler, A.B., Csillag, A., Kuenzel, W., Medina, L., Paxinos, G., Shimizu, T., Striedter, G., Wild, M., Ball, G.F., Durand, S., Gunturkun, O., Lee, D.W., Mello, C.V., Powers, A., White, S.A., Hough, G., Kubikova, L., Smulders, T.V., Wada, K., Dugas Ford, J., Husband, S., Yamamoto, K., Yu, J., Siang, C. \& Jarvis, E.D. (2004) Revised nomenclature for avian telencephalon and some related brainstem nuclei. J. Comp. Neurol., 473, 377414.

Schmidt Koenig, K. (1960) The suns azimuth compass, one factor in the ori entation of homing pigeons. Science, 131, 826828.

Sherry, D.F. \& Vaccarino, A.L. (1989) Hippocampus and memory for food caches in black capped chickadees. Behav. Neurosci., 103, 308318.

Shiflett, M.W., Smulders, T.V., Benedict, L. \& DeVoogd, T.J. (2003) Revers ible inactivation of the hippocampal formation in food storing black capped chickadees (Poecile atricapillus). Hippocampus, 13, 437444.

Vargas, J.P., Petruso, E.J. \& Bingman, V.P. (2004) Hippocampal formation is required for geometric navigation in pigeons. Eur. J. Neurosci., 20, 19371944.

Wagner, G. (1972) Topography and pigeon orientation. In Galler, S.R., Schmidt Koenig, K., Jacobs, G.J. \& Belleville, R.E. (Eds), Animal Orien tation and Navigation. NASA, Washington, DC, pp. 259273.

Wallraff, H.G. (1991) Conceptual approaches to avian navigation systems. In Berthold, P. (Ed.), Orientation in Birds. Birkhauser, Basel, pp. 128165.

Wallraff, H.G. (1994) Initial orientation of homing pigeons as affected by the surrounding landscape. Ethol. Ecol. Evol., 6, 2336.

Wallraff, H.G. (2005) Avian Navigation, Pigeon Homing as a Paradigm. Springer Verlag, Berlin.

Wallraff, H.G. \& Neumann, M.F. (1989) Contribution of olfactory navigation and non olfactory pilotage to pigeon homing. Behav. Ecol. Sociobiol., 25, 293302.

Watanabe, S. \& Bischof, H.J. (2004) Effects of hippocampal lesions on acquisition and retention of spatial learning in zebra finches. Behav. Brain Res., 155, 147152.

Wiltschko, R. \& Wiltschko, W. (2003) Avian navigation, from historical to modern concepts. Anim. Behav., 65, 257272.

Zar, J.H. (1984) Biostatistical Analysis. Prentice Hall, Englewood Cliffs, NJ. 